\title{
Designable elements of integrative learning environments at the boundary of school and work: a multiple case study
}

\author{
Erica Bouw ${ }^{1,2}$ D Ilya Zitter ${ }^{2}$. Elly de Bruijn ${ }^{1,2}$
}

Received: 24 September 2019 / Accepted: 3 September 2020 / Published online: 13 September 2020 (c) The Author(s) 2020

\begin{abstract}
Learning environment designs at the boundary of school and work can be characterised as integrative because they integrate features from the contexts of school and work. Many different manifestations of such integrative learning environments are found in current vocational education, both in senior secondary education and higher professional education. However, limited research has focused on how to design these learning environments and not much is known about their designable elements (i.e. the epistemic, spatial, instrumental, temporal and social elements that constitute the learning environments). The purpose of this study was to examine manifestations of two categories of integrative learning environment designs: designs based on incorporation; and designs based on hybridisation. Cross-case analysis of six cases in senior secondary vocational education and higher professional education in the Netherlands led to insights into the designable elements of both categories of designs. We report findings about the epistemic, spatial, instrumental, temporal and social elements of the studied cases. Specific characteristics of designs based on incorporation and designs based on hybridisation were identified and links between the designable elements became apparent, thus contributing to a deeper understanding of the design of learning environments that aim to connect the contexts of school and work.
\end{abstract}

Keywords Activity Centred Analysis and Design (ACAD) model · Curriculum design · Designable elements $\cdot$ Integrative learning environments $\cdot$ Multiple case study $\cdot$ Schoolwork boundary

\section{Introduction}

Because a universally-recognised characteristic of vocational education is its relation to the world of work, workplace learning or other varieties of practice-based learning are often integrated in the vocational curriculum (Billett 2014; Grollmann 2018). The term vocational education is used here to refer to all education and training for vocations (Billett 2011). The school-work relation that characterises vocational education

Erica Bouw

erica.bouw@hu.nl; erica.bouw@ou.nl

Open University of the Netherlands, PO Box 2960, 6401 DL Heerlen, The Netherlands

2 HU University of Applied Sciences, PO Box 14007, 3508 SB Utrecht, The Netherlands 
has implications for learning environment design, because features from school and from work need to be intentionally combined within the learning environment. Intentionally designed learning environments or systems at the boundary of school and work include authentic goal-directed work activities and physical settings in which learners can practise and be guided by experts from occupational practice (Billett and Choy 2013; Harteis et al. 2014). Such activities and settings are needed to develop the kinds of knowing and skills required to be productive in work, to inform learners about their preferred vocations and to assess their suitability for a vocation (Choy et al. 2018). Thus, work is important not only as a context about which learners need to learn, but also as a context through which students can learn and develop (Guile and Griffiths 2001). However, workplace learning is subject to limitations: the workplace is not always suited as a context for learning because workplace demands tend to override individual and educational goals (Fjellström and Kristmansson 2016), students might be allowed to work only on simple tasks (Nyen and Tønder 2018) or work cannot be paused for explanations (Schaap et al. 2012).

Educators strive to work around such limitations by facilitating connectivity between workplace-based and school-based activities (Griffiths and Guile 2003). However, empirical studies illustrate that connectivity is not easy to achieve: collaboration between workplaces and education providers is problematic (Pylväs et al. 2018; Stenström and Tynjälä 2009) and learners continue to experience difficulties in integrating what they have learned into the contexts of school and work (Baartman and De Bruijn 2011). A stronger connection between the contexts can be achieved through the design of "appropriate arrangements for integration" (Choy et al. 2018, p. 11). The quest to design such integrative arrangements has led to 'fruitful alternatives' to workplace learning (Poortman et al. 2014), which can be used as complementary learning environments alongside workplace learning in vocational curricula. Examples are schoolbased vocational learning (Lindberg 2003), work-integrated learning programmes (Veillard 2012), Industry School Partnerships (Flynn et al. 2016), hybrid configurations (Cremers et al. 2016), Change Laboratory workshops (Morselli et al. 2014) and hybrid learning environments (Zitter et al. 2016).

Despite the large variety of integrative learning environments at the school-work boundary, few studies have addressed their specific design characteristics. Although learning environment research has received growing attention in the last three decades (Zandvliet and Fraser 2018), such studies in vocational education are still relatively scarce (Wesselink and Zitter 2017). A large body of research on learning environments focuses on students' perceptions of the learning environment and on variables affecting these perceptions (e.g. Telli et al. 2006). In vocational education, analogous studies have presented insights into how students' perceptions impact specific learning outcomes, such as self-regulation (Jossberger et al. 2018). Moreover, some studies in vocational education have contributed to our understanding of instruction from an integrative pedagogical perspective (Elvira et al. 2017), of designing learning environments for a specific purpose (e.g. to foster a community of learners; Boersma et al. 2016) and of designing a specific manifestation (e.g. hybrid configurations; Cremers et al. 2016). However, an overall framework with designable features of different types of learning environments in vocational education is still lacking. For educators to be able to make informed design decisions and for scholars to be able to study the effect of these decisions, insights are needed into the specific designable elements of different types of learning environments at the school-work boundary. 


\section{Context of the study}

The context of this study is Dutch vocational education, which includes both senior secondary vocational education and higher professional education (De Bruijn et al. 2017; Smulders et al. 2019). Both levels of education qualify students for occupational practice. The levels correspond with Levels 3-6 of the International Standard Classification of Education (ISCED) and of the European Qualification Framework (EQF). In the Netherlands, vocational education is part of the public education system: government, educational institutes and social partners cooperate to provide labour market-relevant vocational arrangements that also prepare students for participation in society and further study (De Bruijn et al. 2017). Although the Dutch vocational system is primarily school-based, workplace learning is a considerable part of the curriculum and continuous efforts are made to establish connective relationships between workplace learning and learning in schools (Onstenk 2017). In the last decade, this has led to a variety of learning environment designs in which learning and working are 'merged' (Wesselink and Zitter 2017). Even though our study was conducted in Dutch vocational education, the results are anticipated to be relevant for all education in which connectivity between the contexts of school and work is an important issue. The overall aim was to improve understanding of the variety of manifestations of vocational learning environments at the school-work boundary.

\section{Theoretical framework}

In this article, we use the term 'learning environments' to indicate educational arrangements or systems that are designed and managed (Goodyear 2005). These arrangements are embedded in a larger educational programme and influenced by the organisational context of the educational institution (Albashiry et al. 2015; Thijs and van den Akker 2009). By 'learning environment', we refer to both the socio-cultural setting and the physical/digital setting in which learners perform their tasks (Carvalho and Goodyear 2018; Zitter and Hoeve 2012). Tools and artefacts make up the physical setting of the learning environment and co-constitute a range of affordances for learners (Goodyear et al. 2014). Next to the designable elements of a learning environment (i.e. elements that can be purposefully designed; Ellström et al. 2008; Zitter and Hoeve 2012), this study took into account the design rationale for the school-work connection of a learning environment (Bouw et al. 2019). Three rationales have been identified to connect the contexts of school and work: alignment, incorporation and hybridisation (see Fig. 1).

Because school-workplace alignment has been the focus of several studies in the last decade (e.g. Akomaning et al. 2011; Messmann and Mulder 2015; Nieuwenhuis et al. 2017; Poortman et al. 2014), the present study focused on designs based on incorporation and hybridisation. Designs based on these two rationales are considered to be integrative: in designs based on incorporation, aspects of one context are integrated into another context without changing the nature of each practice; and in designs based on hybridisation, school and work contexts are integrated in such a way that new in-between practices emerge at the school-work boundary (Akkerman and Bakker 2011).

To unravel the complexity of integrative learning environment designs, we used a descriptive framework, based on the Activity Centred Analysis and Design (ACAD) model (Carvalho and Goodyear 2018). The ACAD model has its starting point in the presupposition that, although learning cannot be designed, "the physical and social components of 


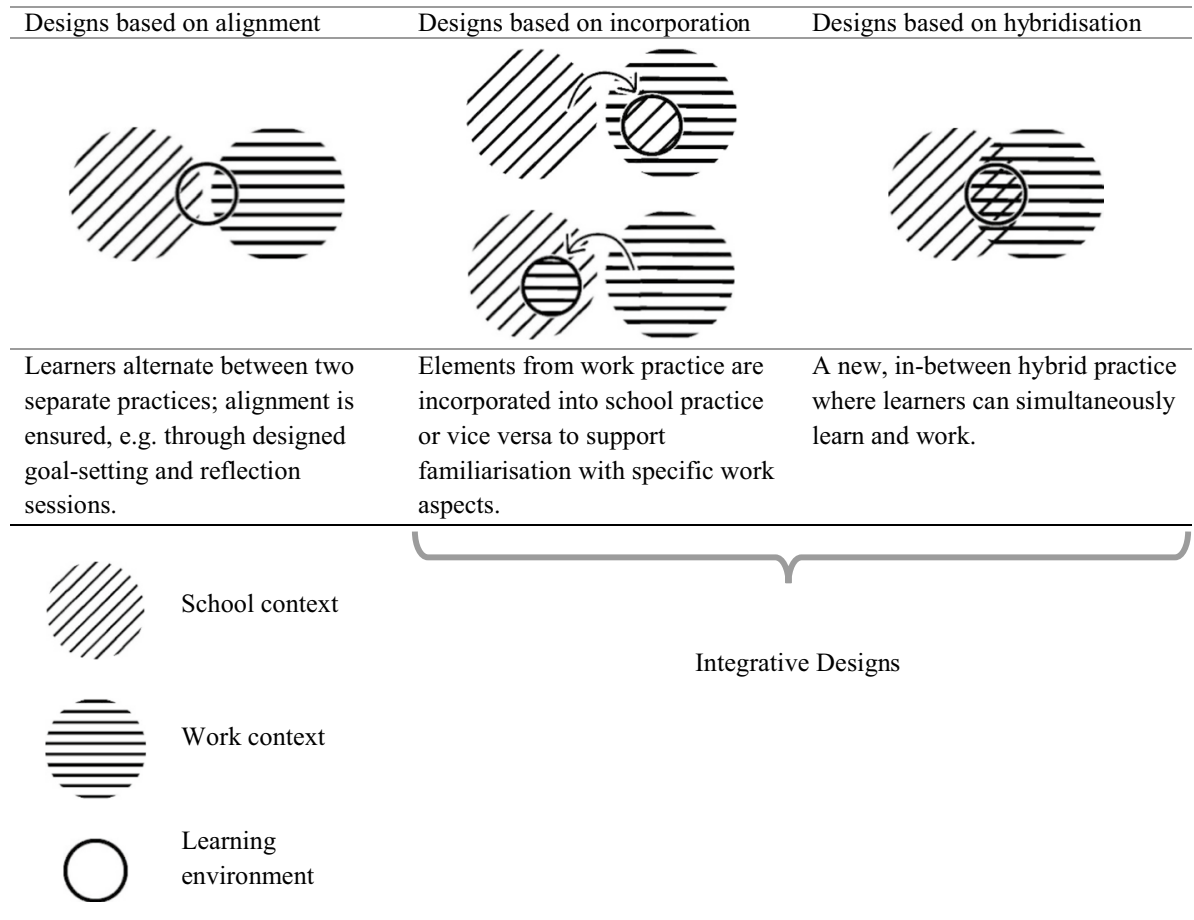

Fig. 1 Three design rationales for the school-work connection (based on Bouw et al. 2019)

the situation in which learning activity unfolds can be designed" (Carvalho and Goodyear 2018 , p. 35, authors' italics). This presupposition acknowledges that human activity tends to be goal-directed and that a design can influence these activities by shaping the physical and social setting and by setting tasks (i.e. suggestions about 'something worth doing'; Goodyear and Carvalho 2014). In the ACAD model, design is a way to invite learners to engage in tasks and activity is emergent and epistemically, physically and socially situated (Carvalho and Goodyear 2018). To include the temporal dimension of activity more explicitly (Engeström 2001), our framework includes time-related aspects of a learning environment design (Zitter and Hoeve 2012), leading to the framework as represented in Fig. 2. The resulting framework distinguishes five designable elements: epistemic, spatial, instrumental, temporal and social elements.

Epistemic elements of a learning environment design are the task characteristics and the task arrangement (Carvalho and Goodyear 2018). These elements are based on the ways of knowing (including skills and attitudes) that are seen as worthwhile in the relevant domain and about how this knowing can best be presented and structured within the curriculum (Carvalho and Goodyear 2018). In the context of vocational education, aimed at supporting students to learn a vocation, epistemic elements are related to the occupation for which learners are being prepared. How people engage in work practice and what that practice affords to learners can have consequences for what they learn (Billett 2001). Thus, a key step in curriculum design is to determine which practices are suited to the specific occupation (Billett and Choy 2013), what kind of tasks learners are supposed to engage in, and 


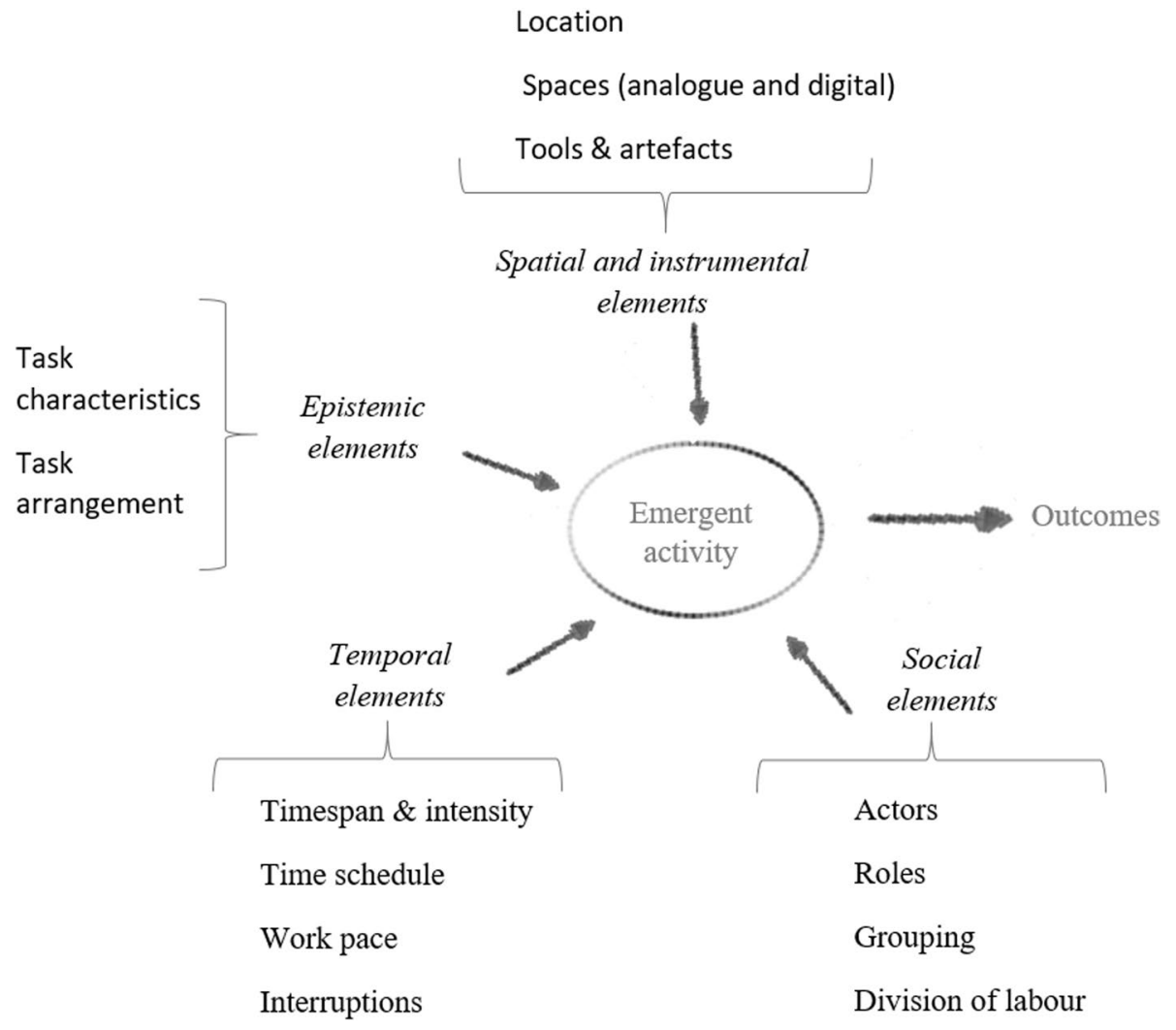

Fig. 2 Descriptive framework: designable elements of learning environments (based on Carvalho and Goodyear 2018; Zitter and Hoeve 2012)

what kind of information they need to perform those tasks (Kirschner and Van Merriënboer 2008).

Spatial and instrumental elements of the learning environment's design include all physical features. Spatial elements are the location (school, work or third location), spaces (analogue or digital) and how these spaces are furnished (e.g. as professional work spaces or as traditional classroom spaces; Bouw et al. 2019; Zitter and Hoeve 2012). Instrumental features include all tools and artefacts needed to perform relevant tasks. In the terminology of the ACAD model, these affordances constitute the set design of the learning environment (Carvalho and Goodyear, 2018). In vocational education, the set design is likely to comprise artefacts that facilitate communication and collaboration between school and work, or so-called 'boundary objects' (Bakker and Akkerman 2014). Professional artefacts that are used in occupational practice can serve as boundary objects and also could be used to enhance the consistency between different tasks within a learning environment (Zitter et al. 2016).

Social elements are all actors present in a learning environment, the roles that they fulfil, how they are grouped and how tasks are appointed to and divided between different actors (i.e. the division of labour). This is called the social design within the ACAD model and it includes all suggestions for how actors might interact (Carvalho and Goodyear 2018). In 
vocational education, learning environments often involve from the contexts of school and work multiple actors who enact educational roles (e.g. coach, learner, assessor) and roles related to the profession (e.g. junior or senior colleague, or managerial roles) (Zitter and Hoeve 2012). Role descriptions can vary from highly-specified role descriptions to functions with multiple roles (Zitter et al. 2011).

In the present study, temporal elements are included in the framework to illuminate the importance of considering affordances related to time. Designable temporal elements include: timespan and intensity of the programme, nature of the time schedule, work pace (including amount of time pressure), and work interruptions to slow down, accelerate or pause the work process for educational purposes (Bouw et al. 2019; Zitter and Hoeve 2012).

Together, the designable elements influence the nature and pace of the emergent activity within a learning environment (i.e. activities in which participants engage). Insights into the variety of designable elements for different manifestations of integrative learning environments can contribute to our understanding of curriculum design in vocational education. The present study aimed at collecting empirical evidence about a purposeful selected variety of learning environments, identifying designable elements and improving understanding of "what is designable in advance, and what is not" (Carvalho and Goodyear 2018, p. 10). Therefore, the following research question was formulated: Which manifestations of integrative learning environment designs can be identified in vocational education? To fully understand the empirical differences and similarities of the two categories of integrative designs, the following related question was posed: What are the specific designable elements of designs based on incorporation and designs based on hybridisation?

\section{Method}

To map the empirical variation of integrative learning environments and uncover the designable elements of real-life manifestations in vocational education, a multiple case study design was chosen (Stake 2013; Yin 2014).

\section{Case definition and selection}

The unit of analysis of each case was a learning environment (i.e. a bounded part of the curriculum). In line with the descriptive framework presented in the introduction (Fig. 2), each unit of analysis comprised the epistemic, spatial, instrumental, social and temporal elements of the learning environment. Cases were selected from a large pool of potential cases that could be accessed via the research group's nationwide network of key figures in Dutch senior secondary and higher professional education. Information-rich cases were identified and selected by combining theory-based and stratified purposeful sampling strategies (Palinkas et al. 2015). Theory-based sampling involved identifying learning environments which might correspond with one of the design categories (i.e. designs based on incorporation or on hybridisation; Fig. 1). We aimed to select at least two cases per category to be able to make statements about different categories (Yin 2014). Furthermore, we wanted to study at least four cases in total to reach a thorough understanding of the central phenomenon (Stake 2013). Cases were selected by studying publicly-accessible information about cases in the pool of potential cases, and then interviewing a key person of promising cases. These interviews centred around school-work connectivity and were 
to confirm our initial conjectures. Stratified purposeful sampling was applied to improve credibility and capture patterns that cut across occupational domains, educational levels, timespan and years of existence of the learning environments:

- Occupational domain: Six different occupational domains were selected.

- Educational level: Both upper secondary Vocational Education and Training (VET; ISCED/EQF Level 3-4) and Higher Professional Education (HPE; ISCED/EQF Level 5-6) were included.

- Timespan within the curriculum: Cases included timespans varying from 10 weeks to more than 2 years (of the 3 or 4 years of the whole educational programme).

- Years of existence: We selected only stable learning environments that had existed for two to more than 10 years.

Using these selection criteria, the selection presented in Table 1 resulted in cases that were located in six different institutions, were spread geographically over the country and included urban and rural areas.

\section{Data collection}

Data were gathered about both the purposeful design and the emergent activity within each learning environment. Multiple data sources were used to ensure rich descriptions, data triangulation and validity of the results (Yin 2014): curriculum documents, an in-depth interview with a key figure in the learning environment, and site visits which included short participant interviews and observations (see Table 2). The number of site visits per case ranged from one to three, depending on the variety of physical settings and planned interactions within the learning environment. Before each visit, the purpose of observations and interviews was discussed with a key figure of the case, who informed the other participants and signed an informed consent form. During observations and before each interview, participants' consent was double-checked orally. No personal data of the participants other than the key-figure were registered; all data were processed anonymously. During the site visits, photographs were taken of artefacts, spaces, instruments and interactions between actors. Actors were interviewed and asked to elaborate on the rationale underlying the activities in which they were (or had been) engaged and about the epistemic, spatial, instrumental, social and temporal elements of those activities. Table 2 shows details of the site visits for each case.

\section{Analysis}

Data analysis codes were developed with the aid of a template, which is a thematicallyorganised table with textual data from the cases and which was verified and modified through data collection and analysis (Cassell et al. 2014). A priori codes of the initial template were based on the presented theoretical framework (Figs. 1, 2) and were related to:

- The design rationale regarding the school-work connection (i.e. 'incorporation' or 'hybridisation').

- The designable elements: epistemic, spatial, instrumental, temporal, social, and their subcategories (e.g. 'spatial-physical space', and 'spatial-digital space'). 


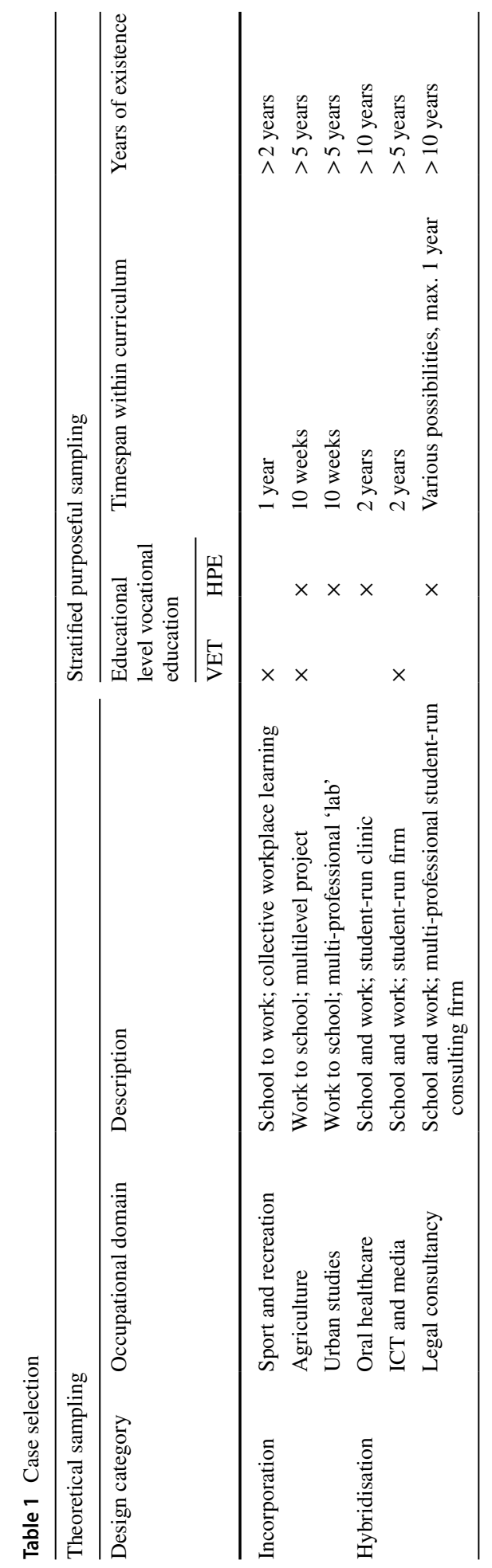




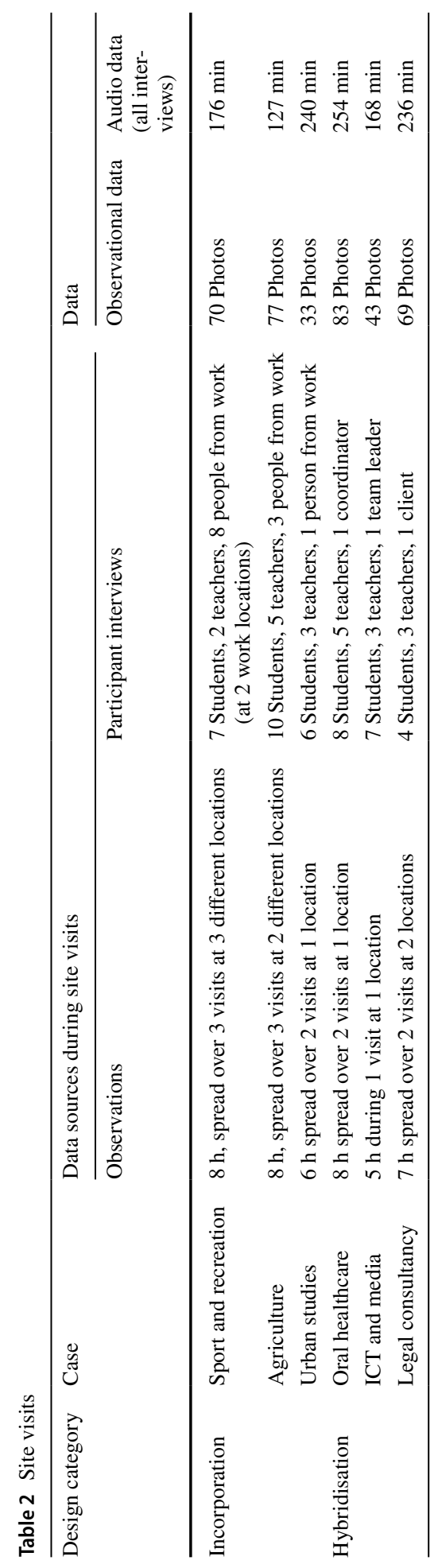


Codes that arose from the data during analysis (e.g. to code experienced 'bottlenecks' mentioned by the actors) were added to the template. The template was discussed within the research group (i.e. together with the second and third author) until consensus was reached.

During within-case analysis, data from the different data sources were combined (audio, documents, photographs) to create case reports. Interviews were the primary data source, corroborated and expanded by findings from other data sources, thus deepening our understanding of the designable elements of the learning environments. Data triangulation took place by coding designable elements across several data sources. For example, a finding about a spatial element (e.g. based on a photograph) was compared with interview excerpts about how the space was being used (audio) and with a curriculum document that explains the design rationale relating to the use of spaces. Thus, findings were based on the convergence of evidence from different data sources (Yin 2014) and processed into case reports, which were enriched with photographs and excerpts from the documents and interviews. The case reports were member-checked with the key figure of the case and consequently adapted. Minor revisions to the case reports resulted from these checks.

Cross-case analysis entailed aggregating findings across the six cases with tables (Yin 2014) and worksheets (Stake 2013). The tables displayed data from the six cases according to categories, thus capturing the findings for each case for each designable element (see "Appendices A-E"). Analysis of the characteristics presented in the tables enabled us to draw cross-case conclusions about the two design categories (incorporation and hybridisation). Stake's worksheet approach was used as a complementary analysis method to determine each case's uniqueness among other cases and to establish the prominence of relevant themes.

\section{Results}

The six cases selected for the purposes of this study were found to represent the two categories of integrative designs: designs based on incorporation and designs based on hybridisation. Table 3 provides an overview of the designable elements of the six cases. This section elaborates the designable elements and the differences and similarities between the incorporation cases and the hybridisation cases. Detailed information about each of the designable elements of the cases can be found in "Appendices A-E".

Sport and Recreation, Agriculture and Urban Studies were selected as designs based on incorporation. Gathered data supported this categorisation: in all three cases, school and work practices preserve their own features while elements from one context are incorporated in the other context. In the Sport and Recreation case, under supervision of a teacher, elements of school practice are incorporated in work practice to familiarise students with the professional field. In the Agriculture and Urban Studies cases, aspects of occupational practice are incorporated in the school setting, where students work together in a way that mimics the reality of their future work setting. In these last two cases, a setting is constructed in which students can experience what it is like to work together with people from different levels of education (Agriculture) and different professions (Urban Studies).

Oral Healthcare, ICT and Media and Legal Consultancy were selected as designs based on hybridisation. This was confirmed by the data from the cases: in all three cases, the learning environment exhibits features of both school and work practices and the object of the learning environment is twofold, namely, focused both on the contribution to learning 

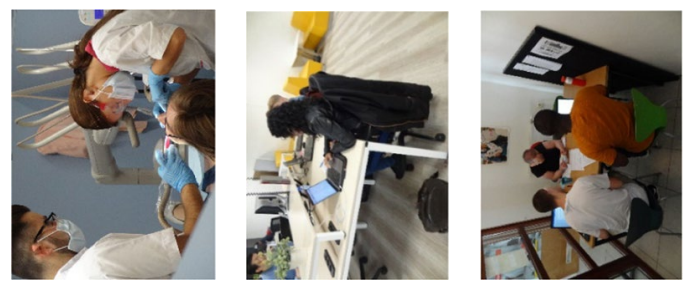

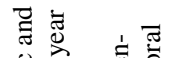

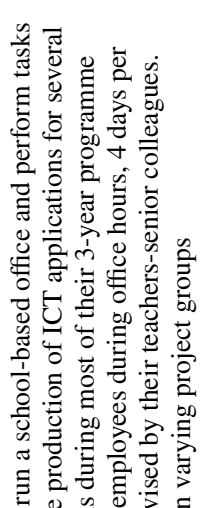

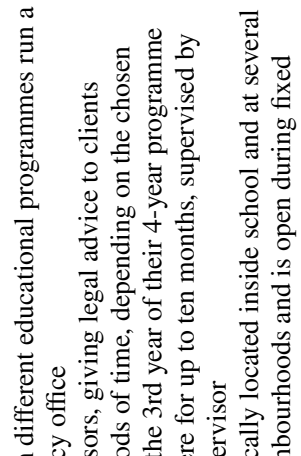

夏总

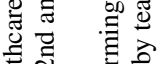

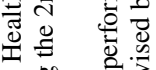

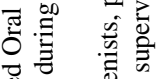

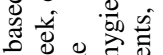

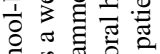

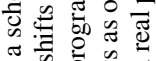

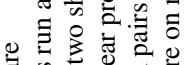

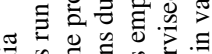

>⿵冂一

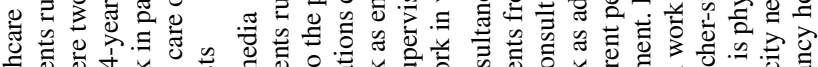

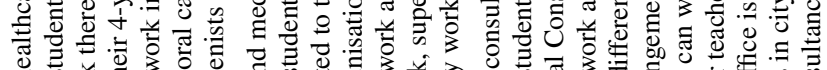
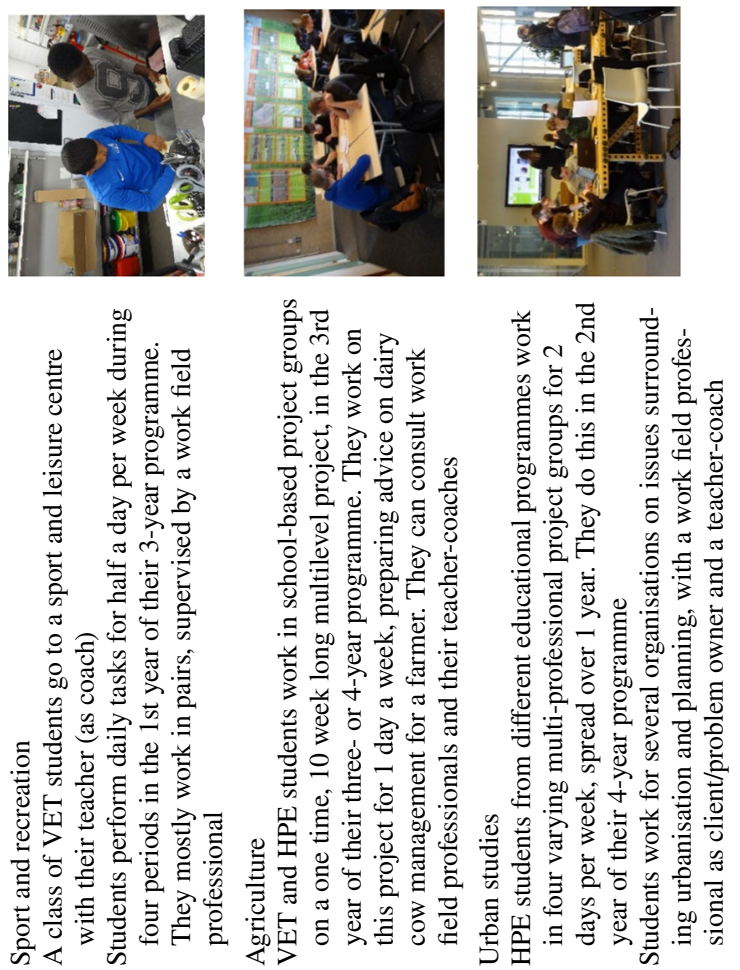
and on the work task (patient care, ICT applications and legal consultancy respectively). The three learning environments have been purposefully designed to provide a professional service in a relatively controlled and safe learning environment.

Table 4 summarises the main similarities and differences between the incorporation cases and the hybridisation cases. The following paragraphs elaborate on each of the designable elements.

\section{Epistemic elements}

All six integrative designs are built around real-life work tasks. A difference between the incorporation cases and the hybridisation cases is that occupational tasks in the three incorporation cases are relatively low-risk, while occupational tasks in the three hybridisation cases are characterised by a higher fidelity level (see also "Appendix A"). As a consequence, the task arrangements within the incorporation cases are less complex: all students can perform tasks from day one with limited instruction. The hybridisation cases require a more refined design in which students can perform both basic and complex tasks in a way that minimises the risk of compromising patients' health and safety (Oral Healthcare), the risk of technical problems with a website (ICT and Media) or the risk of potentially-wrongful legal advice (Legal Consultancy).

\section{Spatial and instrumental elements}

There is no one-on-one relation between the design category and the physical location: both incorporation and hybridisation cases can be school-based, work-based or a combination of both. Sometimes third locations are visited to meet with a client (Agriculture, Urban Studies) or as a field trip (ICT and Media). However, a difference between the incorporation and the hybridisation cases is that, in the incorporation cases, no special physical elements are intentionally added to the learning environment; spaces and artefacts pertain to either the school or the work contexts. In contrast, the spaces in the hybridisation cases are purposefully furnished to look more like, respectively, an office (ICT and Media, Legal Advice) and an oral treatment practice (Oral Healthcare) than a school, while also providing spaces and instruments suited for instruction and teacher consultation. Regarding the instrumental elements in all six integrative cases, boundary objects are found that facilitate communication between school and work actors. These objects are instrumental to both school-purposes (e.g. grading) and work-related purposes (e.g. reporting on the work process): they serve to negotiate the tasks to be executed, monitor students' development and the work progress, and showcase the results (see also "Appendix B").

\section{Temporal elements}

The three incorporation cases have a shorter time span within the curriculum and a lower intensity (in terms of the number of hours per week) than the hybridisation cases. Furthermore, the hybridisation cases have different modalities, depending on the level of the students. For example, in their second year, students can work for $56 \mathrm{~h}$ at the Legal Consultancy office while, in their third year, they usually work there full-time for up to 10 months. Although all cases have fixed weekdays in a weekly schedule, the nature of the schedule differs not only between the two categories, but also within the categories. For instance, 


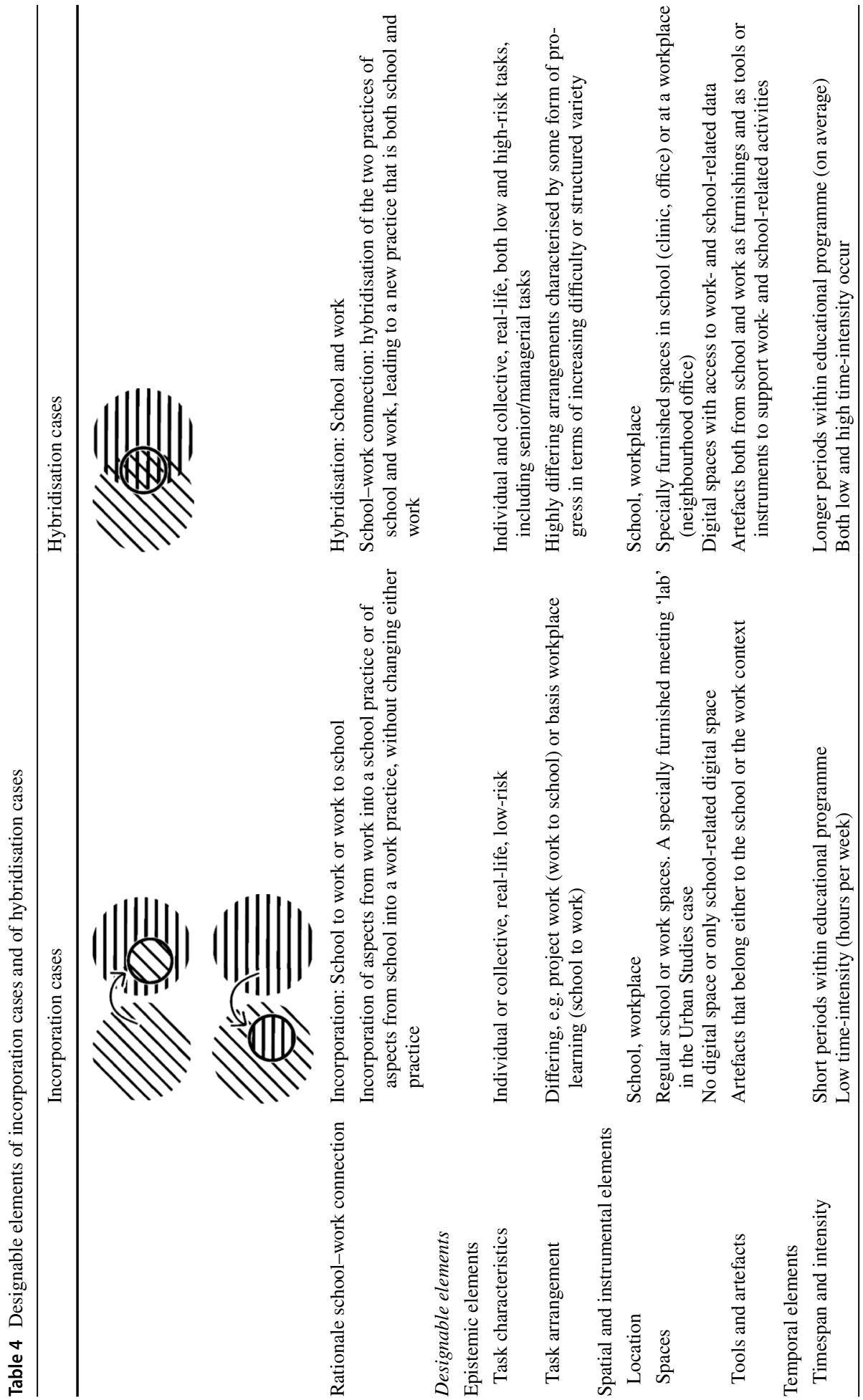




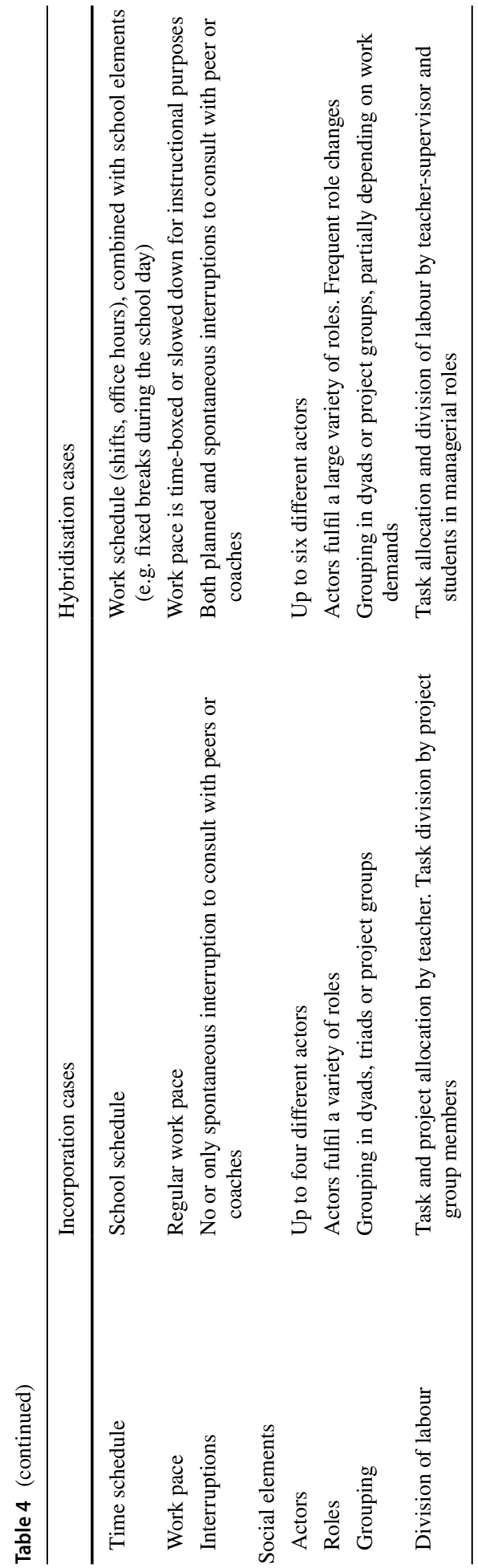


while all three hybridisation cases follow a work-like schedule (office hours and shifts), the ICT and Media case also has collective (school) breaks. Work pace is regular in most cases and intentionally slower than regular work pace (in professional settings) in two of the three hybridisation cases. Only in the Agriculture case, time pressure is intentionally added to the design by having project groups interact with different experts in 15-min rounds. This is done to make the expert meetings more exciting for the students and to ensure that they interact with a large diversity of experts. Work process interruptions for instructional purposes are foreseen in all designs. In the incorporation cases, such interruptions do not have consequences for the work process. In the hybridisation cases, work interruption can be obtrusive when clients are present and have to wait as a consequence of the interruption. Nevertheless, frequent purposeful interruptions are an intentional part of the design to safeguard the correct execution of tasks or to engage in collective problem solving (see also "Appendix C").

\section{Social elements}

All six cases have multiple actors fulfilling a variety of roles in the learning environment, but the role diversity and role complexity differ, as do some features related to grouping and division of labour. Students fulfil roles as peer-learners and as (junior) colleagues in all integrative designs. However, peer coaching is most evident in the three hybridisation cases, for which students are supported to work side-by-side or in an explicit junior-senior hierarchy. For instance, in the Oral Healthcare case and the Legal Consultancy case, it is part of the design that less-experienced students observe and perform simple tasks as junior employees. These junior employees are introduced to the work by students in a managerial role. In all three hybridisation cases, students fulfil such managerial roles, being partly responsible for the organisational structure and daily functioning of the learning environment (e.g. concerning the nature of the services and decisions about work templates).

Teachers have roles as coach, assessor and expert in all the studied cases. Within the three hybridisation cases, they concurrently fulfil a role as senior colleague who can intervene in the work process if the need emerges. In the Oral Healthcare case, for instance, a teacher-dental-hygienist or a teacher-dentist needs to be able to take over and finish a treatment after a complication has arisen. In the ICT and Media case, a teacher-senior colleague might perform tasks that are too complex for the students, but needed to proceed with a client's assignment. In the Legal Consultancy case, a senior teacher colleague might step in during a consultation with a client, for example, when the student-junior colleague has difficulties handling clients' emotions. In the incorporation cases, teachers might be consulted on their expertise, but they do not intervene or participate in the work process as senior colleagues.

In all cases, work field professionals have varying roles such as workplace supervisor, senior colleague, expert or client. In the work-based incorporation case (Sport and Recreation), supervisors are needed at work to give instruction about the tasks, while the schoolbased incorporation cases (Agriculture, Urban Studies) need workplace professionals to provide an assignment. The client role is similar in the three hybridisation cases in which work field professionals are clients who are ordering specific products, such as a website (ICT and Media). In two of the cases, citizens have the role of clients and the work field is represented through partners in the chain, such as the patients' dentist (Oral Healthcare) and legal aid organisations (Legal Consultancy). 
As to grouping and division of labour, in all cases, students are grouped in dyads, triads or (project) groups with a teacher as coach (in the incorporation cases) or as workplace supervisor (in the hybridisation cases). Furthermore, all six designs have some kind of kick-off meeting at the start of a project or stand-up meeting at the beginning of a working day. These meetings are guided by a teacher-coach, student-project leader or teacher-workplace supervisor. Teachers have a role in the division of labour in all learning environments but, in the hybridisation cases, they share part of these tasks with students in managerial roles.

Overall analysis of the social design of the six integrative cases showed that hybridisation cases are characterised by a larger number and variety of actors involved (see also “Appendix D"). In all cases, actors fulfil several roles but, within the hybridisation cases, actors switch more frequently between roles. Also, students in these cases change roles both horizontally_focusing on a different task—and vertically_adopting a senior colleague role or one of the managerial roles (see also "Appendix E").

\section{Conclusions and discussion}

The purpose of this research was to improve understanding of the design of integrative learning environments at the school-work boundary. Six cases were selected for studying manifestations of integrative learning environments and their designable elements, with specific attention to the differences and similarities between designs based on incorporation and designs based on hybridisation. Three of the selected learning environments were hypothesised as being manifestations of designs based on incorporation, and three as manifestations of designs based on hybridisation. This initial categorisation was confirmed by the data: in the incorporation cases, aspects of work were incorporated in school or aspects of school were incorporated in work; and the three hybridisation cases were purposefully designed as in-between practices. The specific designable elements of these six manifestations were described with the use of a descriptive framework (Fig. 2), largely based on the ACAD model (Carvalho and Goodyear 2018). Although the number of cases was limited, conclusions about the two categories of integrative designs and about the designable elements of these categories can be drawn.

Similarities between incorporation designs and hybridisation designs include the centrality of real-life work tasks, the use of boundary objects that facilitate communication between school and work, and the variety of roles that actors fulfil in a learning environment. Differences between incorporation designs or hybridisation designs can be identified across all of the designable elements and include a higher fidelity level of the occupational tasks, because they are more realistic and complex, and more evidence of using peer coaching, senior-junior roles and role changes for actors in the hybridisation designs. Moreover, while teachers usually do not participate in the work process in the incorporation designs, they regularly have a role both as a learning coach and as a senior colleague in the hybridisation designs, in which the division of labour can be a shared task between teachers and students in, for example, managerial roles.

We found interrelations between the designable elements. For instance, learning environments with less-elaborate epistemic designs (as found in the incorporation cases), with tasks that require less prior knowledge (epistemic), could be suitable at an early stage in an educational programme and for a short period of time (temporal). Furthermore, because the tasks are more low-risk and can be performed relatively independently by learners 
(epistemic), fewer different actors and roles are needed within the learning environment (social) and few intentional interruptions appear to be required (temporal). In contrast, a more-elaborated epistemic design (as found in the hybridisation cases) seems to correspond with more-frequent work interruptions (temporal) to monitor a correct execution of the task or to offer additional instruction (social). This additional support is added to the design to prevent endangering patient safety or customer satisfaction (epistemic). A consequence can be that the teacher has an additional responsibility (social), namely, quality assurance of the final product (Oonk et al. 2016). In fact, it is likely that the complex epistemic design of learning environments based on hybridisation generally corresponds with an elaborate role design, because a wide variety of roles need to be fulfilled (social) to be within both the production scope and the learning scope of such a learning environment. This is in line with studies on hybrid learning environments that identified a range of roles that are diversified in terms of function and seniority (Zitter and Hoeve 2012).

The link between epistemic and physical elements seems to be determined mainly by the nature of the tasks. In the examined incorporation cases, the tasks at hand required few specific physical affordances. However, relatively simple simulations in healthcare, which can be characterised as incorporation designs, require specifically-equipped spaces and specific instruments for learners to execute the tasks (e.g. a urinary catheterisation procedure; Kneebone et al. 2005). Such suitable physical affordances can have a positive effect on learning opportunities of the learning environment, especially if they are accompanied by a slower work pace (Sheehan et al. 2017). This also illustrates the link between physical elements and temporal elements which, in our study, became visible in two cases in which we witnessed a slower work pace than the regular pace (temporal) because learners needed time to develop the needed competences.

A link between the temporal and social designable elements that we encountered in our study regarded seniority and shared student-teacher control: in the three hybridisation cases, students would fulfil senior tasks after they had spent a minimum amount of time in the learning environment. Students with more experience, or otherwise acquired seniority, fulfilled tasks related to the design and management of the learning environment (social).

\section{Limitations and suggestions for further research}

Regarding the context of the study, a limitation of the presented research is that all studied cases were part of the Dutch education system. Transferability of the findings is enhanced by providing contextual information about the Dutch education system and detailed descriptions of the selected cases. Moreover, the universal nature of connectivity issues when educating or training for vocations leads us to assume transferability of the findings. Nonetheless, transfer of findings to other educational systems (e.g. Asian and African countries) always requires taking into account the "institutional provisions, infrastructure, and social sentiments" of those countries (Billett 2011, p. ix).

A methodological limitation is that, although a systematic case-study approach was used, site visits were relatively short and spread over a maximum of 6 months. An approach that was more longitudinal would have enriched understanding about how a design develops over the years and which designable elements are more likely to be adjusted. Furthermore, a consequence of our focus on cases in secondary vocational and higher professional education is that potentially rich cases in other educational contexts were excluded. In addition, although several actors from the work context were interviewed, our study was largely informed by actors from the school context. Validation of the findings by actors from the 
work context is called for. In general, studies combining school and work perspectives could contribute to a common language and thus potentially to a stronger school-work connectivity (Wesselink et al. 2010).

The focus of our study was generating design knowledge about learning environment designs as a product, not about design as a process. Nonetheless, insights into design categories and designable elements can be of added value to the design process because reflection on, and decisions about, the product being designed impact the design process and vice versa (Reymen et al. 2006). An interesting direction for further research would be the characteristics of a design process when there is involvement of actors from different contexts (school and work), as is often the case with learning designs at the school-work boundary. Such studies might also take into account the ongoing and increasingly-collaborative nature of design processes (Buus and Georgsen 2018; Muñoz-Cristóbal et al. 2018).

\section{Implications and conclusion}

The presented insights into learning environment design at the school-work boundary extend current knowledge about the facilitation of work-related learning. Integrative designs seem to potentially compensate some of the limitations of workplace learning mentioned in the introduction, such as limited task complexity and difficulties with work interruptions. An intentionally-designed integrative learning environment can facilitate students in performing a large variety of tasks (from simple to complex, including managerial tasks), afford access to tools and expertise, and allow more time for the tasks. However, providing these settings does not guarantee that students perceive them in the way in which they were intended: the function of a design is to make recommendations about tasks, spaces, artefacts, actors and temporal elements that might be useful and about roles that should be adopted, while recognising that learners can ignore these recommendations and not identify the affordances provided or regard them in ways other than intended (Markauskaite and Goodyear 2014). In fact, the emergent activity in the implemented curriculum is bound to deviate from the intended design (Zitter et al. 2016). How learners engage in the tasks and settings arranged for them largely depends on their interests, capacities and cognitive experience (Billett 2014).

Nevertheless, findings from other studies lead us to presume that careful attention to the design of learning environments can have a positive effect on the competencies that are developed (Oonk et al. 2017). Furthermore, specific design features of integrative designs appear to have a positive effect on learners' engagement and appreciation. For instance, a study in initial vocational education showed that, in learning environments that allow students to collaborate in life-like vocational activities with increasing complexity, students perceive themselves as learning in a more shared, meaningful, reflective and transfer-oriented way than in more traditional learning programmes (Boersma et al. 2016). Students' appreciation has also been reported about hybrid learning environments which promote self-directed learning and working on real-life problems (Cremers et al. 2016). Similar 
findings have also been reported in a study in an academic setting in which problem-based learning environments were valued by the students as powerful for enhancing learning (Dochy et al. 2005). However, although learning environment design seems to influence learners, further studies are needed for a deeper understanding of the relation between the design and the learning processes generated by the design (Thompson et al. 2013).

This present research contributes to such further studies by offering empirical support for the theoretical categorisation presented in the introduction between designs based on alignment, incorporation and hybridisation (Fig. 1). Furthermore, the study provides additional foundations for the design of learning environments by presenting specific epistemic, spatial, instrumental, social and temporal designable elements of each type of design. Thus, we have shown that our framework, based on the ACAD model and extended with temporal elements, is useful as a descriptive framework for vocational learning environments and can serve as a basis for future learning environment research. Further operationalisation could be advisable in future studies, such as adding insights from more-elaborate task-analysis methods (Jonassen 2014; Van Merriënboer and Kester 2008) and from recent scholarly work on epistemic artefacts (Markauskaite and Goodyear 2017).

Practically, this study contributes to insights into integrative learning environments in vocational education and how they can be designed, as well as possible variations in the design of learning environments, depending on the design rationale for the school-work connection. These findings might serve as a hold for educational designers when considering and discussing the possibilities for designing or adapting vocational curricula. By improving the school-work connection of learning environments and carefully selecting the designable elements, educators can contribute to better support for vocational students that strive to connect the two contexts of school and work. With the examples presented from the cases, designers can be more sensitive to the possibilities of adapting epistemic, spatial, instrumental, temporal and social elements of integrative learning environments at the school-work boundary.

Open Access This article is licensed under a Creative Commons Attribution 4.0 International License, which permits use, sharing, adaptation, distribution and reproduction in any medium or format, as long as you give appropriate credit to the original author(s) and the source, provide a link to the Creative Commons licence, and indicate if changes were made. The images or other third party material in this article are included in the article's Creative Commons licence, unless indicated otherwise in a credit line to the material. If material is not included in the article's Creative Commons licence and your intended use is not permitted by statutory regulation or exceeds the permitted use, you will need to obtain permission directly from the copyright holder. To view a copy of this licence, visit http://creativecommons.org/licenses/by/4.0/.

\section{Appendix A}

See Table 5. 


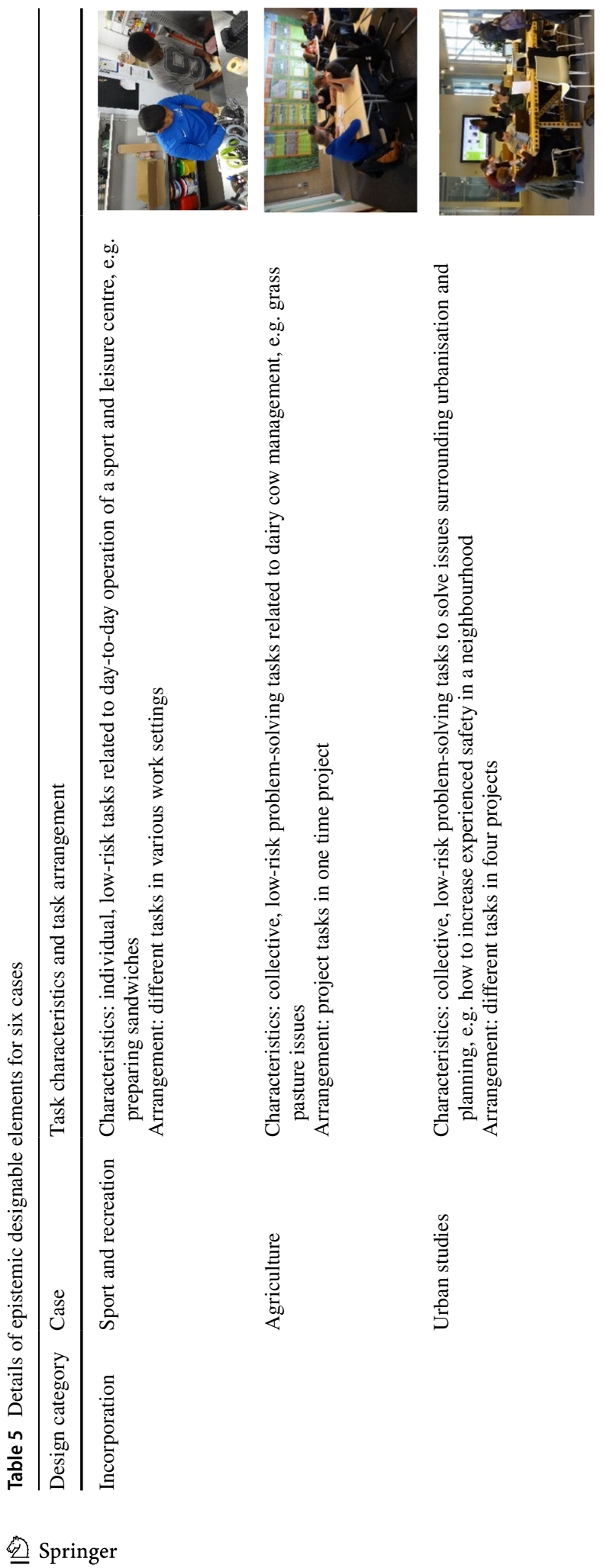




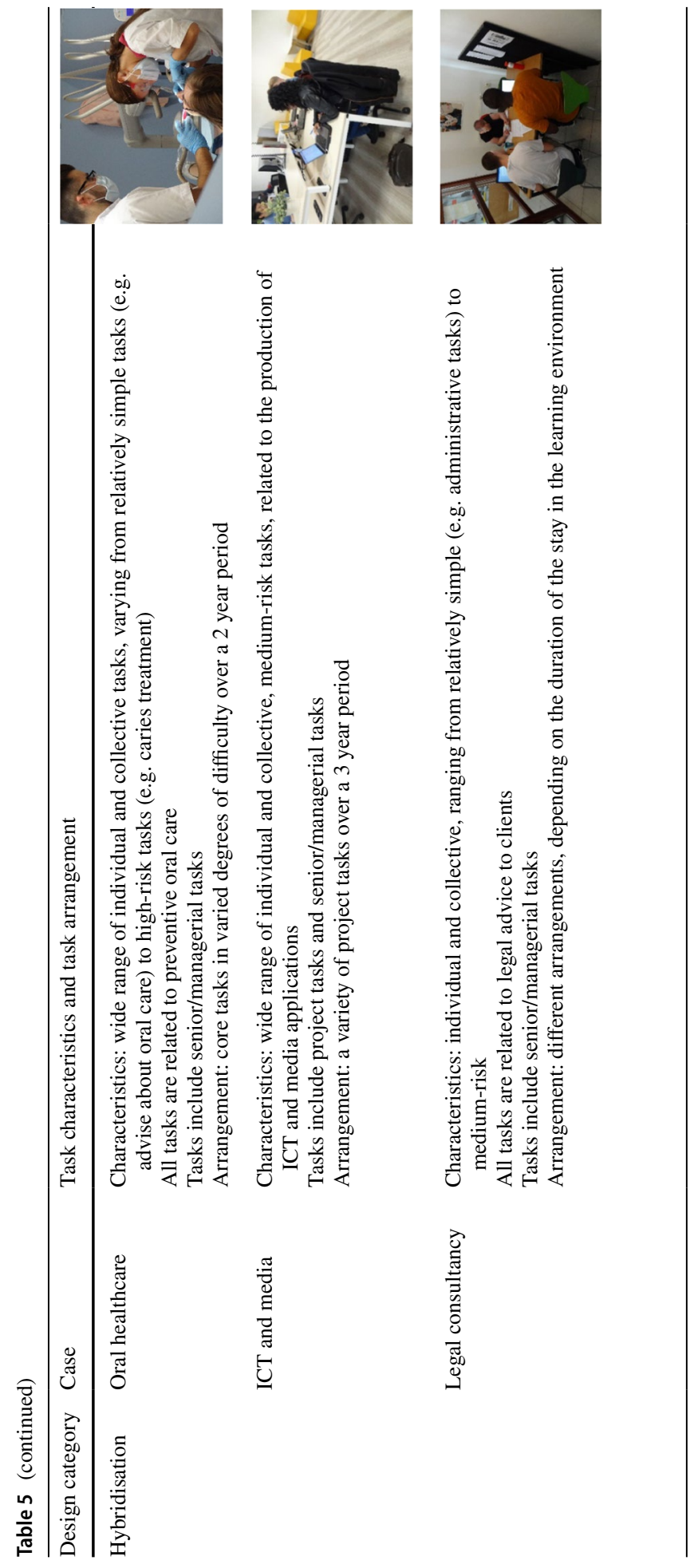




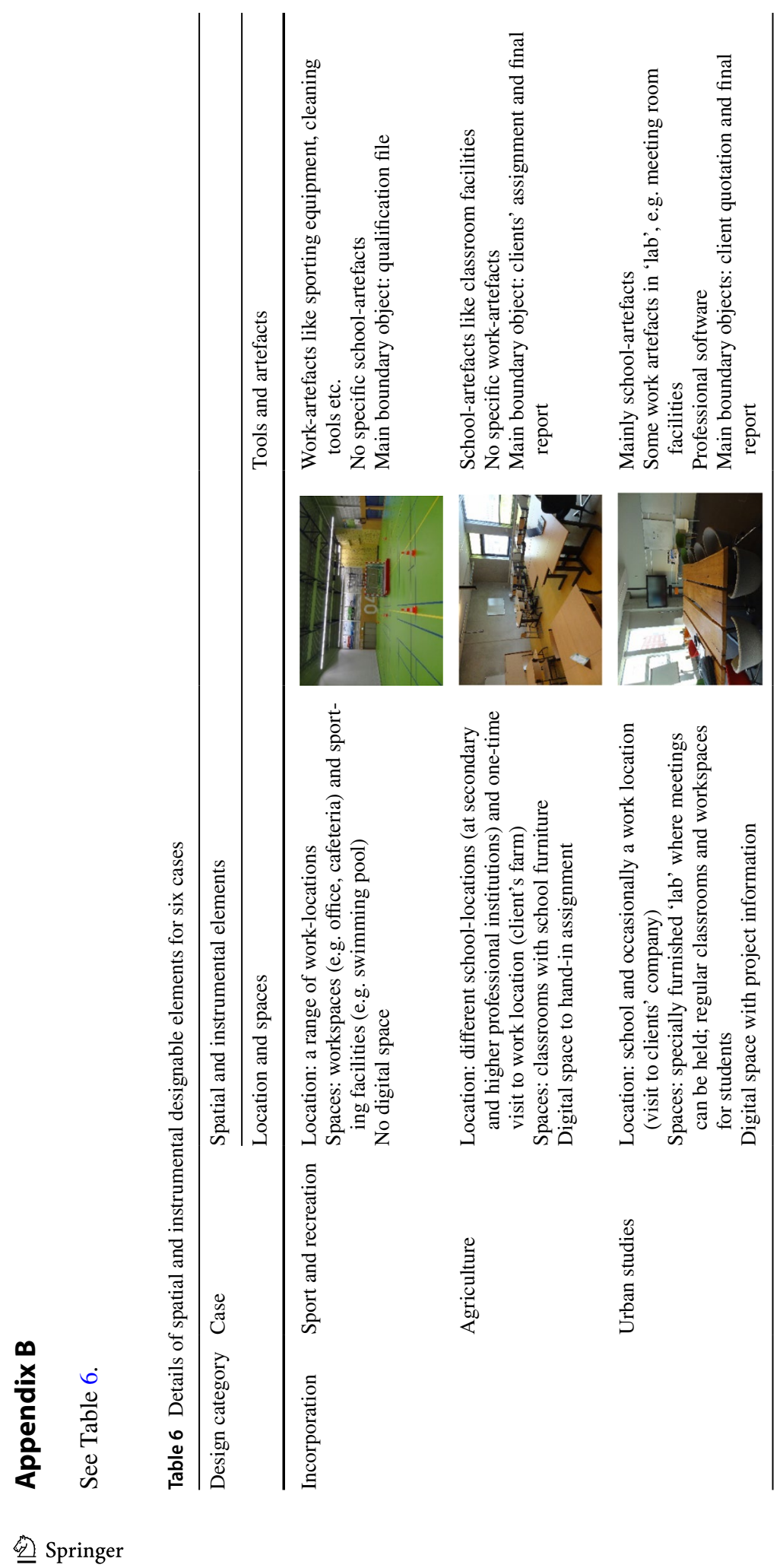




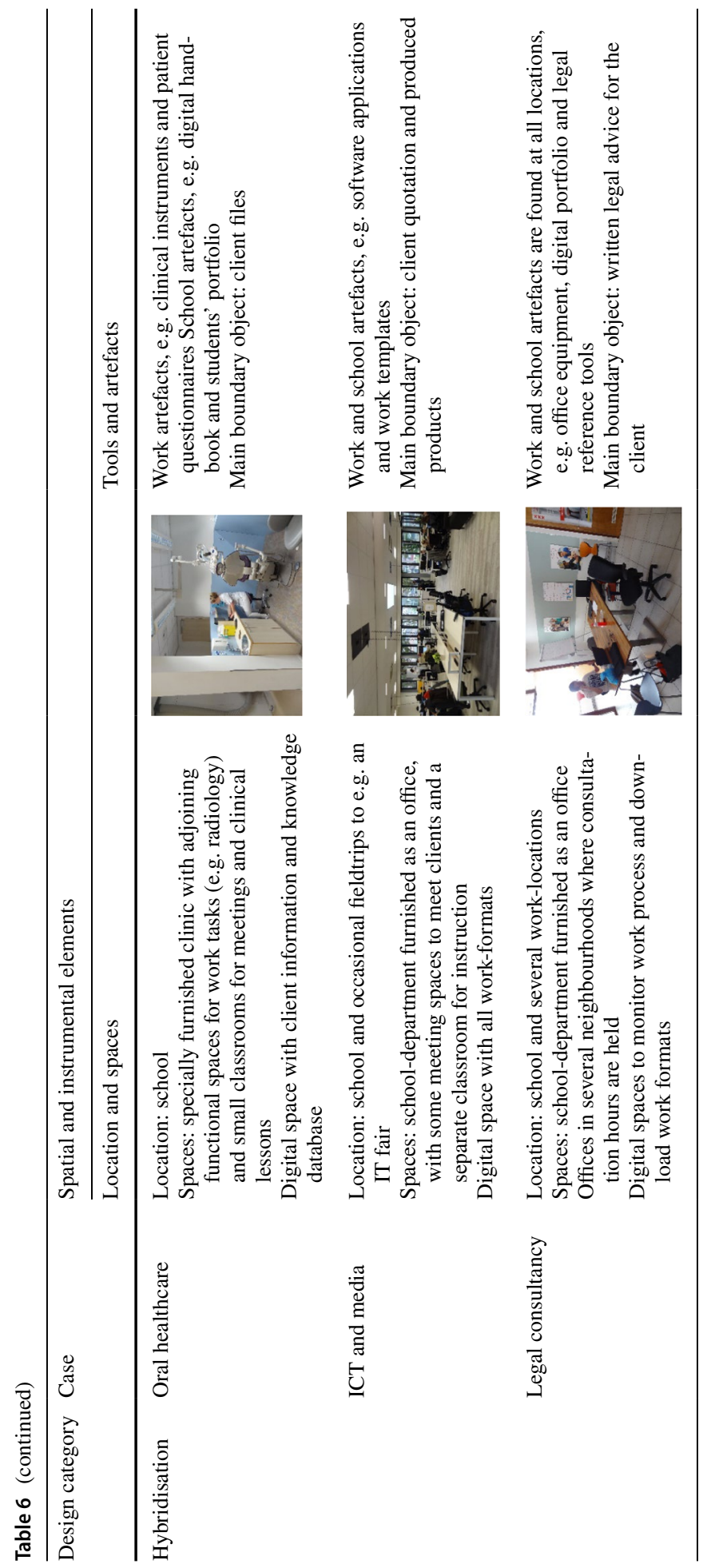




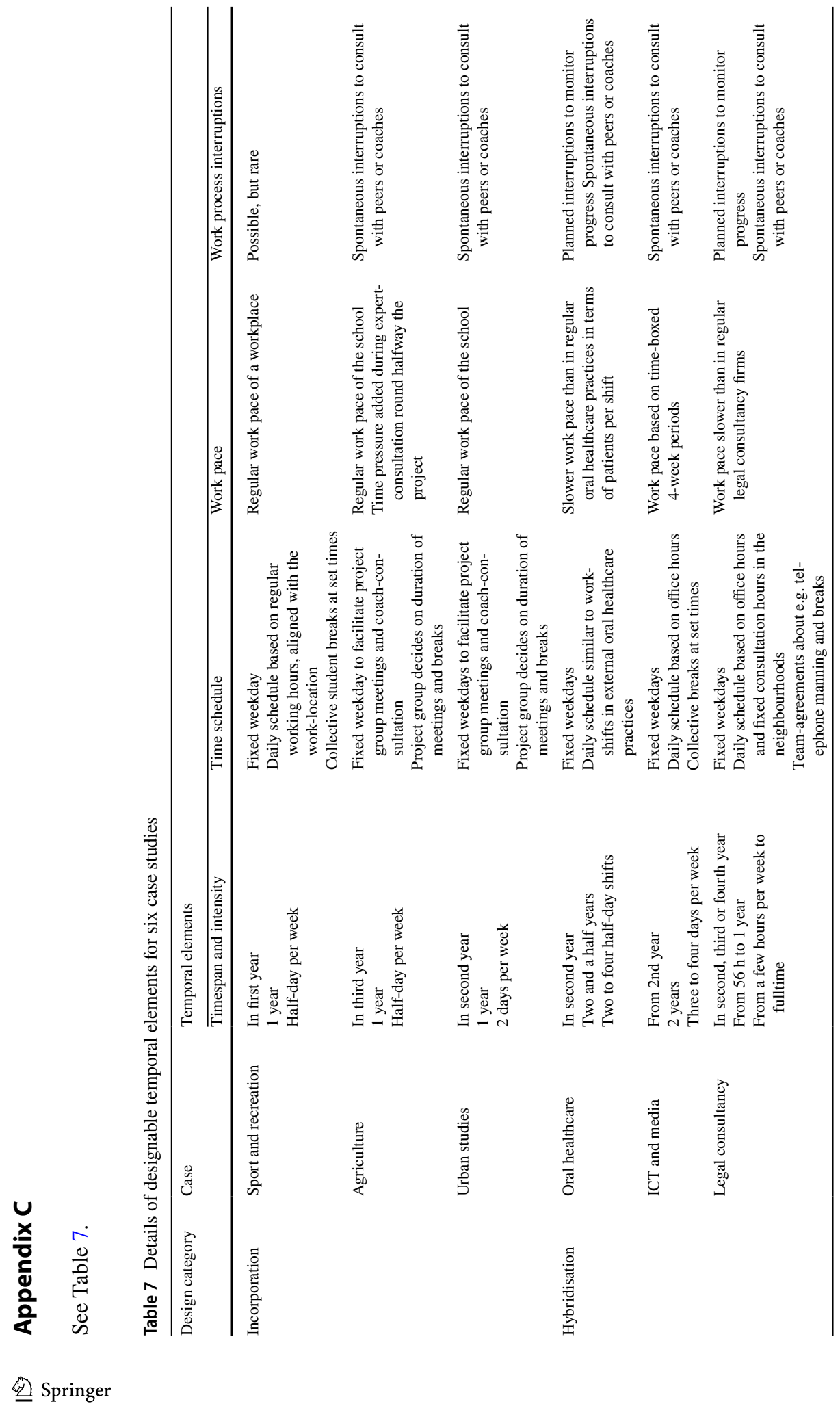




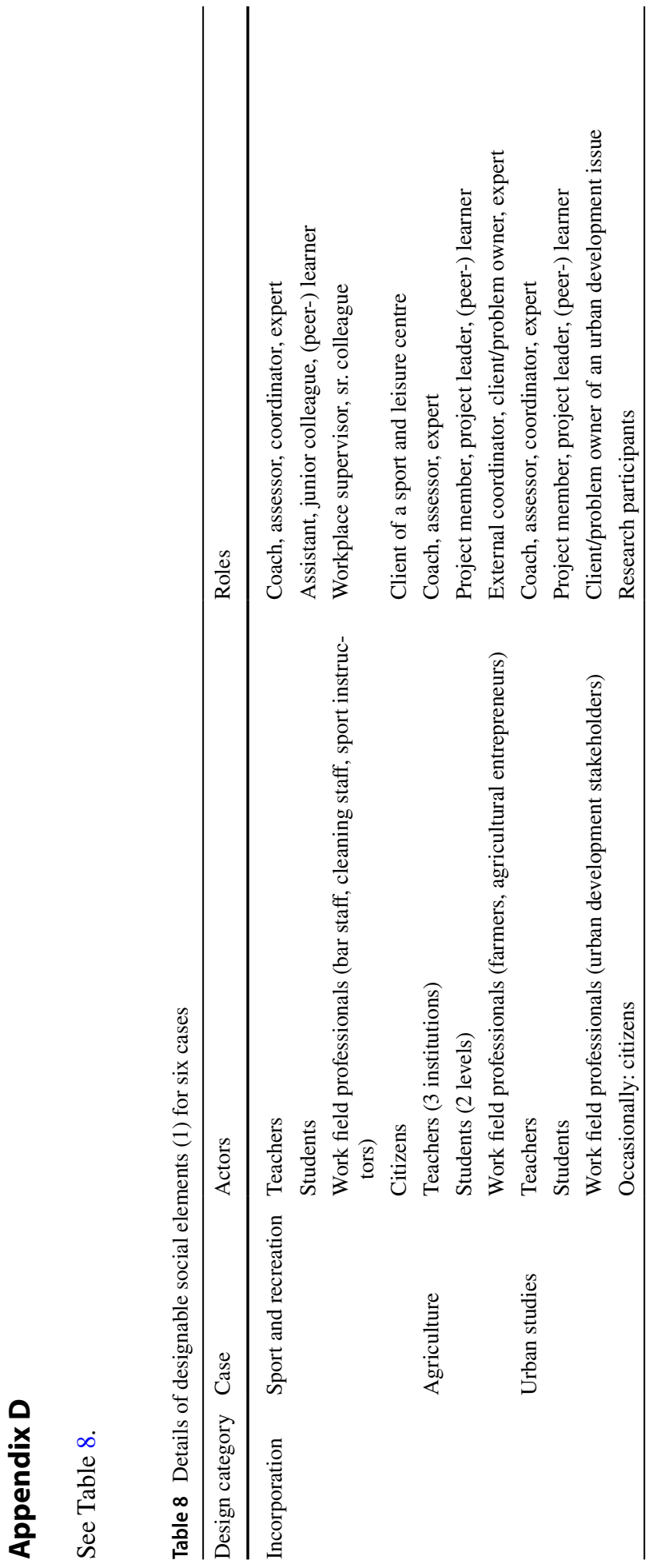




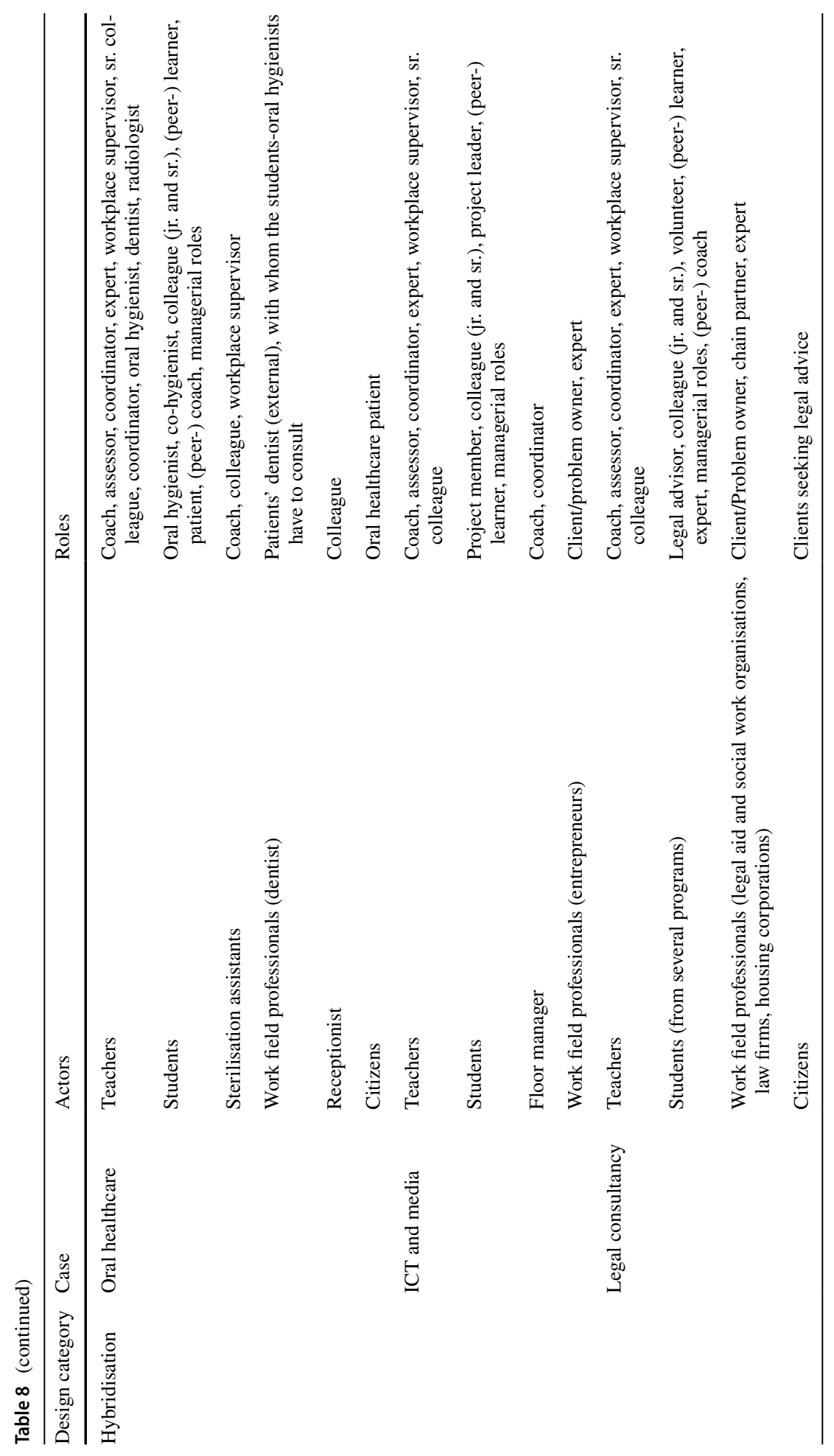




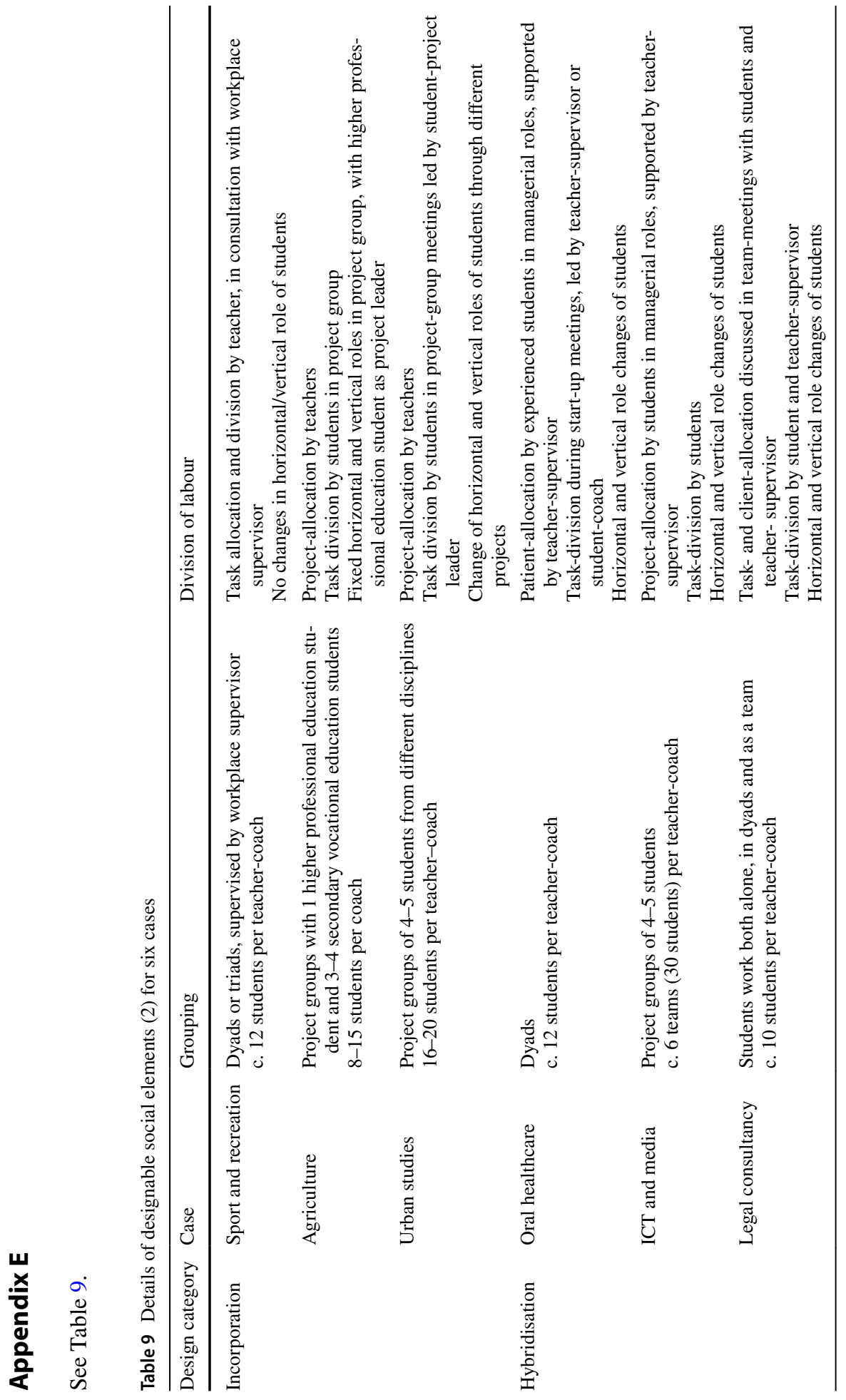




\section{References}

Akkerman, S., \& Bakker, A. (2011). Boundary crossing and boundary objects. Review of Educational Research, 81(2), 132-169. https://doi.org/10.3102/0034654311404435.

Akomaning, E., Voogt, J. M., \& Pieters, J. M. (2011). Internship in vocational education and training: Stakeholders' perceptions of its organisation. Journal of Vocational Education and Training, 63(4), 575-592. https://doi.org/10.1080/13636820.2011.590222.

Albashiry, N. M., Voogt, J. M., \& Pieters, J. M. (2015). Curriculum design practices of a vocational community college in a developing context: Challenges and needs. Community College Journal of Research and Practice, 39(12), 1137-1152. https://doi.org/10.1080/10668926.2014.942894.

Baartman, L. K. J., \& De Bruijn, E. (2011). Integrating knowledge, skills and attitudes: Conceptualising learning processes towards vocational competence. Educational Research Review, 6(2), 125-134. https://doi.org/10.1016/j.edurev.2011.03.001.

Bakker, A., \& Akkerman, S. (2014). Learning by crossing boundaries between school and work. Pedagogische Studiën, 91(1), 8-23.

Billett, S. (2001). Knowing in practice: Re-conceptualising vocational expertise. Learning and Instruction, 11(6), 431-452. https://doi.org/10.1016/S0959-4752(00)00040-2.

Billett, S. (2011). Vocational education: Purposes, traditions and prospects. New York: Springer. https ://doi.org/10.1007/978-94-007-1954-5.

Billett, S. (2014). Integrating learning experiences across tertiary education and practice settings: A socio-personal account. Educational Research Review, 12, 1-13. https://doi.org/10.1016/j.edure v.2014.01.002.

Billett, S., \& Choy, S. (2013). Learning through work: Emerging perspectives and new challenges. Journal of Workplace Learning, 25(4), 264-276. https://doi.org/10.1108/13665621311316447.

Boersma, A., ten Dam, G., Wardekker, W., \& Volman, M. (2016). Designing innovative learning environments to foster communities of learners for students in initial vocational education. Learning Environments Research, 19, 107-131. https://doi.org/10.1007/s10984-015-9203-4.

Bouw, E., Zitter, I., \& De Bruijn, E. (2019). Characteristics of learning environments at the boundary between school and work-A literature review. Educational Research Review, 26, 1-15. https://doi. org/10.1016/J.EDUREV.2018.12.002.

Buus, L., \& Georgsen, M. (2018). A learning design methodology for developing short learning programmes in further and continuing education. Journal of Interactive Media in Education, 2018(1), 8. https://doi.org/10.5334/jime.469.

Carvalho, L., \& Goodyear, P. (2018). Design, learning networks and service innovation. Design Studies, 55, 1-27. https://doi.org/10.1016/j.destud.2017.09.003.

Cassell, C., Symon, G., \& King, N. (2014). Using templates in the thematic analysis of text. In C. Cassell \& G. Symon (Eds.), Essential guide to qualitative methods in organizational Research (pp. 256-270). Thousand Oaks: Sage. https://doi.org/10.4135/9781446280119.n21.

Choy, S., Wärvik, G.-B., \& Lindberg, V. (2018). Integration between school and work: Developments, conceptions and applications. In S. Choy, G. B. Wärvik, \& V. Lindberg (Eds.), Integration of vocational education and training experiences: Technical and vocational education and training: Issues, concerns and prospects (Vol. 29, pp. 3-18). New York: Springer. https://doi. org/10.1007/978-981-10-8857-5_1.

Cremers, P. H. M., Wals, A. E. J., Wesselink, R., \& Mulder, M. (2016). Design principles for hybrid learning configurations at the interface between school and workplace. Learning Environments Research, 19(3), 309-334. https://doi.org/10.1007/s10984-016-9209-6.

De Bruijn, E., Billett, S., \& Onstenk, J. (2017). Vocational education in the Netherlands. In E. De Bruijn, S. Billett, \& J. Onstenk (Eds.), Enhancing teaching and learning in the Dutch vocational education system (pp. 3-36). New York: Springer. https://doi.org/10.1007/978-3-319-50734-7_1.

Dochy, F., Segers, M., Bossche, P. Van Den, \& Struyven, K. (2005). Students' perceptions of a problem-based learning environment. Learning Environments Research, 8(1), 41-66. https://doi. org/10.1007/s10984-005-7948-x.

Ellström, E., Ekholm, B., \& Ellström, P. (2008). Two types of learning environment. Journal of Workplace Learning, 20(2), 84-97. https://doi.org/10.1108/13665620810852250.

Elvira, Q., Imants, J., Dankbaar, B., \& Segers, M. (2017). Designing education for professional expertise development. Scandinavian Journal of Educational Research, 61(2), 187-204. https://doi. org/10.1080/00313831.2015.1119729.

Engeström, Y. (2001). Expansive learning at work: Toward an activity theoretical reconceptualization. Journal of Education and Work, 14(1), 133-156. https://doi.org/10.1080/13639080123238. 
Fjellström, M., \& Kristmansson, P. (2016). Learning as an apprentice in Sweden: A comparative study on affordances for vocational learning in school and work. Education + Training, 58(6), 629-642. https://doi.org/10.1108/ET-12-2015-0113.

Flynn, M. C., Pillay, H., \& Watters, J. J. J. (2016). Industry school partnerships: Boundary crossing to enable school to work transitions across three targeted industries. Journal of Education and Work, 29(3), 1-16. https://doi.org/10.1080/13639080.2014.934789.

Goodyear, P. (2005). Educational design and networked learning: Patterns, pattern languages and design practice. Australasian Journal of Educational Technology. https://doi.org/10.14742/ajet.1344.

Goodyear, P., \& Carvalho, L. (2014). Framing the analysis of learning network architectures. In L. Carvalho \& P. Goodyear (Eds.), The architecture of productive learning networks (pp. 48-70). Philadelphia: Routledge. https://doi.org/10.4324/9780203591093.

Goodyear, P., Carvalho, L., \& Dohn, N. (2014). Design for networked learning: framing relations between participants' activities and the physical setting. Ninth International Conference on Networked Learning, 2014, 137-144.

Griffiths, T., \& Guile, D. (2003). A connective model of learning: The implications for work process knowledge. European Educational Research Journal, 2(1), 56-73. https://doi.org/10.2304/ eerj.2003.2.1.10.

Grollmann, P. (2018). Varieties of "duality": Work-based learning and vocational education in international comparative research. In S. Choy, G. B. Wärvik, \& V. Lindberg (Eds.), Integration of vocational education and training experiences. Technical and vocational education and training: Issues, concerns and prospects (Vol. 29, pp. 63-82). New York: Springer. https://doi. org/10.1007/978-981-10-8857-5_4.

Guile, D., \& Griffiths, T. (2001). Learning through work experience. Journal of Education and Work, 14(1), 113-131. https://doi.org/10.1080/13639080020028738.

Harteis, C., Rausch, A., \& Seifried, J. (2014). Discourses on professional learning: On the boundary between learning and working. In C. Harteis, A. Rausch, \& J. Seifried (Eds.), Discourses on professional learning. Professional and practice-based learning (pp. 1-7). New York: Springer. https:// doi.org/10.1007/978-94-007-7012-6_1.

Jonassen, D. H. (2014). Task analysis methods for instructional design. Philadelphia: Routledge. https:// doi.org/10.4324/9781410602657.

Jossberger, H., Brand-Gruwel, S., van de Wiel, M. W. J., \& Boshuizen, H. (2018). Learning in workplace simulations in vocational education: A student perspective. Vocations and Learningy, 11, 179-204. https://doi.org/10.1007/s12186-017-9186-7.

Kirschner, P., \& Van Merriënboer, J. J. G. (2008). Ten steps to complex learning: A new approach to instruction and instructional design. In T. L. Good (Ed.), 21st century education: A reference handbook (pp. 244-253). Thousand oaks: Sage. https://doi.org/10.1111/j.1467-8535.2008.00870_9.x.

Kneebone, R. L., Kidd, J., Nestel, D., Barnet, A., Lo, B., King, R., et al. (2005). Blurring the boundaries: Scenario-based simulation in a clinical setting. Medical Education, 39(6), 580-587. https:// doi.org/10.1111/j.1365-2929.2005.02110.x.

Lindberg, V. (2003). Learning practices in vocational education. Scandinavian Journal of Educational Research, 47(2), 157-179. https://doi.org/10.1080/00313830308611.

Markauskaite, L., \& Goodyear, P. (2014). Tapping into the mental resources of teachers' working knowledge: Insights into the generative power of intuitive pedagogy. Learning, Culture and Social Interaction, 3(4), 237-251. https://doi.org/10.1016/j.lcsi.2014.01.001.

Markauskaite, L., \& Goodyear, P. (2017). Epistemic fluency and professional education (Vol. 14). New York: Springer. https://doi.org/10.1007/978-94-007-4369-4.

Messmann, G., \& Mulder, R. H. (2015). Conditions for apprentices' learning activities at work. Journal of Vocational Education and Training, 67(4), 578-596. https://doi.org/10.1080/13636820.2015.1094745.

Morselli, D., Costa, M., \& Margiotta, U. (2014). Entrepreneurship education based on the change laboratory. International Journal of Management Education, 12(3), 333-348. https://doi.org/10.1016/j. ijme.2014.07.003.

Muñoz-Cristóbal, J. A., Hernández-Leo, D., Carvalho, L., Martinez-Maldonado, R., Thompson, K., Wardak, D., et al. (2018). 4FAD: A framework for mapping the evolution of artefacts in the learning design process. Australasian Journal of Educational Technology, 34(2), 16-34. https://doi. org/10.14742/ajet.3706.

Nieuwenhuis, L., Hoeve, A., Nijman, D.-J., \& Van Vlokhoven, H. (2017). Pedagogic-didactic design of workplace learning in initial vocational education: An international review study. Kenniscentrum Kwaliteit van Leren: HAN.

Nyen, T., \& Tønder, A. H. (2018). Development of vocational skills through integration of practical training periods in school based vocational education in Norway. In S. Choy, G. B. Wärvik, \& V. 
Lindberg (Eds.), Integration of vocational education and training experiences. Technical and vocational education and training: Issues, concerns and Prospects (Vol. 29, pp. 227-241). New York: Springer. https://doi.org/10.1007/978-981-10-8857-5_12.

Onstenk, J. (2017). Work-based learning (WBL) in Dutch vocational education: Connecting learning places, learning content and learning processes. In E. De Bruijn, S. Billett, \& J. Onstenk (Eds.), Enhancing teaching and learning in the Dutch vocational education system (pp. 219-243). New York: Springer. https://doi.org/10.1007/978-3-319-50734-7_11.

Oonk, C., Gulikers, J., \& Mulder, M. (2016). Educating collaborative planners: Strengthening evidence for the learning potential of multi-stakeholder regional learning environments. Planning Practice \& Research, 31(5), 533-551. https://doi.org/10.1080/02697459.2016.1222108.

Oonk, C., Gulikers, J., \& Mulder, M. (2017). Educating boundary crossing planners: Evidence for student learning in the multistakeholder regional learning environment. Journal of Planning Education and Research, 1(14), 1-14. https://doi.org/10.1177/0739456X17737598.

Palinkas, L. A., Horwitz, S. M., Green, C. A., Wisdom, J. P., Duan, N., \& Hoagwood, K. (2015). Purposeful sampling for qualitative data collection and analysis in mixed method implementation research. Administration and Policy In Mental Health, 42(5), 533-544. https://doi.org/10.1007/s10488-013-0528-y.

Poortman, C. L., Reenalda, M., Nijhof, W. J., \& Nieuwenhuis, L. F. M. (2014). Workplace learning in dual higher professional education. Vocations and Learning, 7(2), 167-190. https://doi.org/10.1007/s1218 6-014-9111-2.

Pylväs, L., Rintala, H., \& Nokelainen, P. (2018). Integration for holistic development of apprentices' competences in Finland. In S. Choy, G. B. Wärvik, \& V. Lindberg (Eds.), Integration of vocational education and training experiences. Technical and vocational education and training: Issues, concerns and prospects (Vol. 29, pp. 125-143). New York: Springer. https://doi.org/10.1007/978-981-10-8857-5_7.

Reymen, I. M. M. J., Hammer, D. K., Kroes, P. A., Van Aken, J. E., Dorst, C. H., Bax, M. F. T., et al. (2006). A domain-independent descriptive design model and its application to structured reflection on design processes. Research in Engineering Design, 16(4), 147-173. https://doi.org/10.1007/s0016 3-006-0011-9.

Schaap, H., Baartman, L., \& De Bruijn, E. (2012). Students' learning processes during school-based learning and workplace learning in vocational education: A review. Vocations and Learning, 5(2), 99-117. https://doi.org/10.1007/s12186-011-9069-2.

Sheehan, D., Jowsey, T., Parwaiz, M., Birch, M., Seaton, P., Shaw, S., et al. (2017). Clinical learning environments: Place, artefacts and rhythm. Medical Education, 51(10), 1049-1060. https://doi. org/10.1111/medu.13390.

Smulders, H., Cox, A., \& Westerhuis, A. (2019). Vocational education and training in Europe: Netherlands. Cedefop ReferNet VET in Europe reports 2018.

Stake, R. E. (2013). Multiple case study analysis. New York: Guilford Press.

Stenström, M.-L., \& Tynjälä, P. (Eds.). (2009). Towards integration of work and learning. Berlin: Springer. https://doi.org/10.1007/978-1-4020-8962-6.

Telli, S., Cakiroglu, J., \& Den Brok, P. (2006). Turkish secondary education students' perceptions of their classroom learning environment and their attitude towards biology. In D. Fisher \& M. S. Khine (Eds.), Contemporary approaches to research on learning environments: Worldviews (pp. 517-542). Singapore: World Scientific Publishing Co. https://doi.org/10.1142/9789812774651_0022.

Thijs, A., \& van den Akker, J. (2009). Curriculum in development. SLO Netherlands Institute for Curriculum Development.

Thompson, K., Ashe, D., Carvalho, L., Goodyear, P., Kelly, N., \& Parisio, M. (2013). Processing and visualizing data in complex learning environments. American Behavioral Scientist, 57(10), 1401-1420. https ://doi.org/10.1177/0002764213479368.

Van Merriënboer, J. J. G., \& Kester, L. (2008). Whole task models in education. In J. M. Spector, M. D. Merrill, J. Van Merriënboer, \& M. P. Driscoll (Eds.), Handbook of research on educational communications and technology (pp. 441-456). Philadelphia: Routledge.

Veillard, L. (2012). Transfer of learning as a specific case of transition between learning contexts in a French work-integrated learning programme. Vocations and Learning, 5(3), 251-276. https://doi.org/10.1007/ s12186-012-9076-y.

Wesselink, R., De Jong, C., \& Biemans, H. J. A. (2010). Aspects of competence-based education as footholds to improve the connectivity between learning in school and in the workplace, 3, 19-38. https:// doi.org/10.1007/s12186-009-9027-4.

Wesselink, R., \& Zitter, I. (2017). Designing competence-based vocational curricula at the school-work boundary. In E. De Bruijn, S. Billett, \& J. Onstenk (Eds.), Enhancing teaching and learning in the Dutch vocational education system (pp. 175-194). New York: Springer. https://doi.org/10.1007/9783-319-50734-7_9. 
Yin, R. K. (2014). Case study research: Design and methods (5th ed.). Thousand Oaks: Sage.

Zandvliet, D. B., \& Fraser, B. (Eds.). (2018). Thirty years of learning environments. Leiden: Brill I Sense. https://doi.org/10.1163/9789004387720.

Zitter, I., De Bruijn, E., Simons, P. R. J., \& Ten Cate, T. J. (2011). Adding a design perspective to study learning environments in higher professional education. Higher Education, 61(4), 371-386. https://doi. org/10.1007/s10734-010-9336-4.

Zitter, I., \& Hoeve, A. (2012). Hybrid learning environments: Merging learning and work processes to facilitate knowledge integration and transitions. OECD Education Working Papers (no. 8). https://doi. org/10.1787/5k 97785 xwdvf-en.

Zitter, I., Hoeve, A., \& De Bruijn, E. (2016). A design perspective on the school-work boundary: A hybrid curriculum model. Vocations and Learning, 9(1), 111-131. https://doi.org/10.1007/s1218 6-016-9150-y.

Publisher's Note Springer Nature remains neutral with regard to jurisdictional claims in published maps and institutional affiliations. 